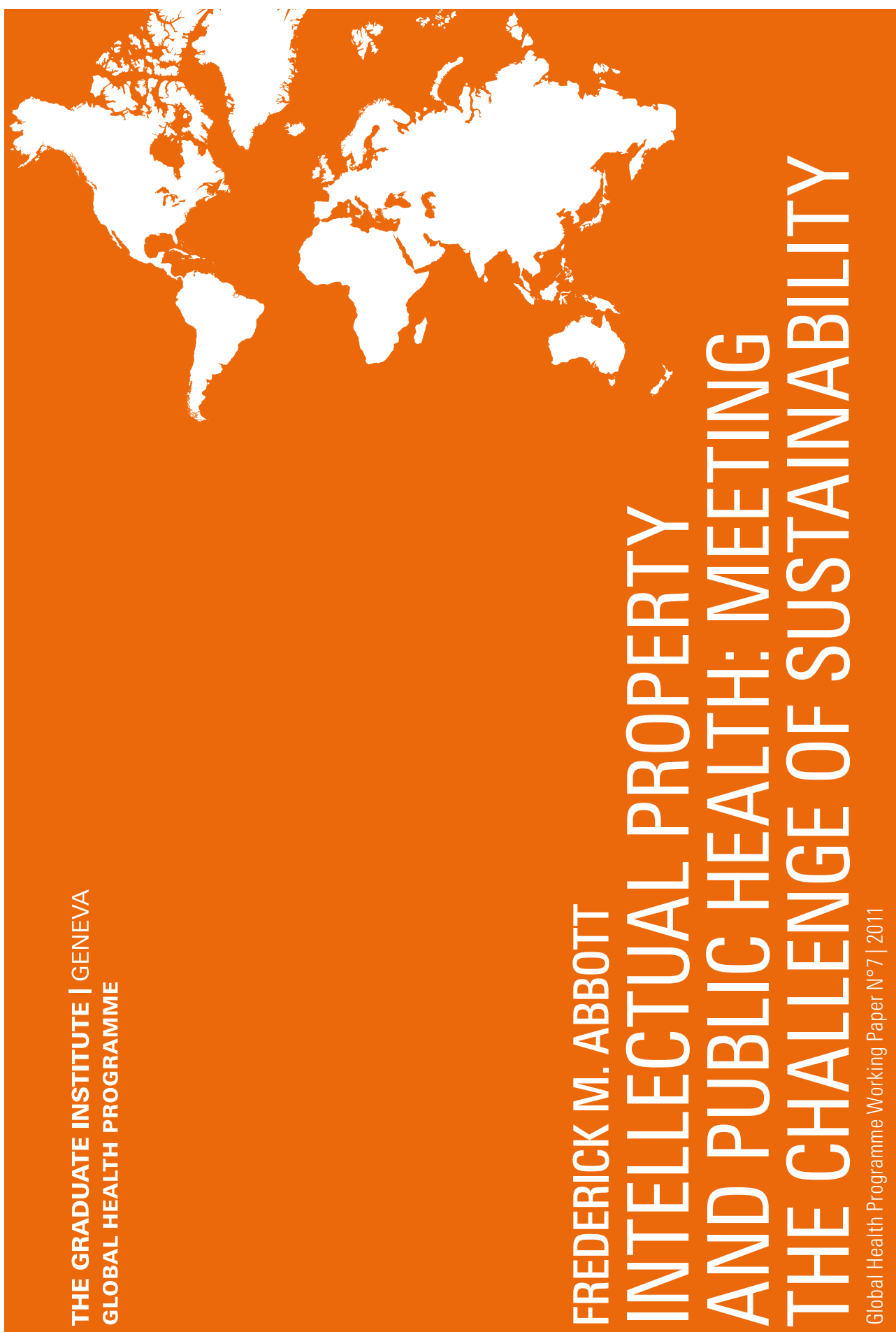




\section{FREDERICK M. ABBOTT \\ INTELLECTUAL PROPERTY AND PUBLIC HEALTH: MEETING THE CHALLENGE OF SUSTAINABILITY}

Tn the decade since the Doha Declaration was adopted, significant 1 progress has been made in addressing problems associated with innovation and access to medicines, including through expanded financial support for procurement and distribution of treatments and vaccines and the establishment of new research and development (R\&D) mechanisms. There has been enhanced cooperation among WHO, WIPO and the WTO. Nevertheless, significant gaps remain in placing the development and supply of medicines to the world's population on a sustainable footing; gaps that are exacerbated by the present trend toward restrained government spending. This paper reflects on the political and legal constellation making progress on global public health matters difficult, and on economic and scientific trends in the medicines sector that may affect policy over the next decade. A sustainable medicines supply system should proceed from "first principles", encompassing financing mechanisms to assure that essential medicines are provided for all, while affording opportunity to countries at all levels of development to offer access to advanced treatments on a fair compensation basis. Improved mechanisms to incentivize R\&D are necessary and feasible. First principles should encompass rational prescribing based on the best interests of the patient, and should attend to regulation and enforcement adequate to assure quality, safety and efficacy. Development of a sustainable system could require some modification to the WTO TRIPS Agreement, but this should not be a determinative factor in considering an improved international framework. A new mechanism for global coordination of medicines strategy may be helpful.

GLOBAL HEALTH PROGRAMME

132 , rue de Lausanne

P.0. Box 136

1211 Geneva 21

Switzerland

T +41229085700

E globalhealth@graduateinstitute.ch

Key Words

Dublic health, Intellectual property, Multilateral institutions, TRIPS 1 Agreement, Doha Declaration, Essential medicines, Research and development, Patents, Licensing, Financing mechanisms. 

HEALTH: MEETING THE CHALLENGE OF SUSTAINABILITY'

\section{THE DECADE SINCE DOHA}

$T^{t}$ is ten years since the adoption of the Doha Declaration on the ITRIPS Agreement and Public Health ${ }^{2}$. The intervening decade has witnessed positive changes in terms of a more serious commitment by the international community to address fundamental public health problems, such as the spread of HIV/AIDS and the threat of pandemic disease. Governments have provided direct and indirect financial support for the purchase and distribution of urgently needed treatments and vaccines. At the level of multilateral institutions, there is improved cooperation and coordination among the World Health Organization (WHO), the World Intellectual Property Organization (WIPO) and the World Trade Organization (WTO). The grass-roots movement of non-governmental organisations (NGOs) - concerned with access to medicines - has, in important instances, been transformed into institutions, such as the Drugs for Neglected Diseases initiative (DNDi) and the Medicines Patent Pool (MPP). These institutions are directly involved in research initiatives, as well as efforts to improve production and distribution for developing countries. Major philanthropic organisations have entered the medicines arena and provided funding and support for research and development (R\&D), and procurement.

* Edward Ball Eminent Scholar Professor of International Law, Florida State University College of Law, USA. This paper was prepared by the author in the capacity of consultant to the Global Health Programme, Graduate Institute of International and Development Studies, Geneva. The paper was reviewed by members of the secretariats of WHO, WIPO and the WTO, and its content benefits should not be understood to represent the views of thor reflects solely the views of its author, and from discussions with Professor Nick Drager, formerly of the WHO Secretariat.

1 Prepared for presentation at the 5th High-Level Symposium on Global Health Diplomacy,

organised by the Global Health Programme of the Graduate Institute, Geneva, 23 November 2011 2 Declaration on the TRIPS Agreement and Public Health (14 November 2001). Doc. WT/MIN(01)/ 
The social forces underlying the Doha Declaration led to a global awareness about the problems involving the prevention and treatment of disease - problems that once resided in the shadows. In short, in the decade since the adoption of the Doha Declaration, there have been significant and positive developments in identifying the characteristics of the public health problems that require research and development on the medicines needed to treat diseases; progress has also been made in identifying gaps in the global public infrastructure for supplying existing and future treatments and vaccines.

\section{POLITICAL AND ECONOMIC SOURCES OF TENSION}

The TRIPS Agreement ${ }^{3}$ represented a partial solution to a problem identified by multinational originator pharmaceutical companies and their home country governments. It established a set of baseline rules for patent protection that extended to developing countries in the interests of stemming freeriding on R\&D and related investment ${ }^{4}$. Developing country enterprises would be limited in the scope of the drugs they could produce and market ${ }^{5}$. From the standpoint of the multinational originator pharmaceutical companies and their home country governments, the solution was partial because it recognised that public health interests could override patent protection, and that there are acceptable variations in the characteristics of such protection $^{6}$.

3 Agreement on Trade-Related Aspects of Intellectual Property Rights, Marrakesh Agreement Results of The Uruguay Round of Multilateral Trade Negotiations, p. 321, World Trade Organization, 1999 [hereinafter TRIPS Agreement]. Available at www.wto

4 See Abbott, Frederick M. and Reichman, Jerome H. 'The Doha Round's Public Health Legacy: Strategies for the Production and Diffusion of Medicines Under the Amended TRIPS Provisions' in Journal of International Economic Law, vol. 10, p. 921, Oxford University Press, 2007.

5 Prior to adoption of the WTO TRIPS Agreement, private sector originator pharmaceutical companies focused on protecting their R\&D investments in the markets where they returned the bulk of their profits, namely in the OECD countries. In some important developing country markets, patent protection for pharmaceutical products was not available. In others, patent protection may have been available, but there were wide variations in substantive rules and enforcement practices. as they foresaw an acceleration of growth in developing countries. The WTO TRIPS Agreement was negotiated to extend and secure a baseline of patent protection for pharmaceutical products in developing country markets. Then and now, the markets of least-developed countries remain of low interest to the originator 6 See generally UNCTAD-ICTSD. Resource Book on TRIPS and Development, Cambridge University Press, 2005.
The period following the entry into force of the TRIPS Agreement was marked by an excess of aggression among the originator pharmaceutical companies and their lawyers, at least initially backed by the European Commission and the US government. The tipping point came when action was taken against the government of Nelson Mandela in South Africa over its adoption of the Medicines and Related Substances Control Amendment Act of 1997, which was adopted to implement South Africa's 1996 drugs policy ${ }^{7}$. There was a great deal wrong with the actions of the originator companies in South Africa. Two of the main features of the 1997 act that concerned the companies (generic substitution and price controls) were not covered by the TRIPS Agreement and the third - parallel importation - was clearly permitted by the TRIPS Agreement. This did not prevent a broadside attack against the South African government for acting inconsistently with its international obligations under the TRIPS Agreement, an attack that coincided with a mushrooming HIV/AIDS epidemic.

The US government withdrew its support from the originator companies (conceding that the legislation was consistent with the TRIPS Agreement), but the companies continued with legal action at the Pretoria High Court. NGOs such as Médecins Sans Frontières (MSF), Oxfam and Consumer Project on Technology (the predecessor to KEI) strongly protested the action of the originator companies, and the results were widely publicised in the international media. At the time, it was extremely disappointing that there was no public reaction from the WTO senior leadership as the TRIPS Agreement was being invoked for matters that it either did not address, or that it addressed differently from what was being claimed. WHO sent the author of this paper to South Africa to assist the government in defending against the action by the companies. The International Bureau of WIPO provided support in terms of access to its negotiating records and information concerning the drafting of the South African legislation as it related to intellectual property - drafting that had originally emanated from WIPO headquarters. In the end, the originator companies had no op-

7 See 't Hoen, Ellen F.M. The Global Politics of Pharmaceutical Monopoly Power: Drug patents, access, innovation and the application of the WTO Doha Declaration on TRIPS and Public Health AMB Diemen, 2009; and Abbott, Frederick M. WTO TRIPS Agreement and its Implications for Access to Medicines in Developing Countries. Study Paper 2a. Commission on Intellectual Property Rights, 2002 . 
tion but to withdraw their lawsuit and pay the South African government's legal fees.

Although concerns had been brewing for some time among developing countries and NGOs, it was events in South Africa that triggered the movement towards the Doha Declaration and, in particular, the demand that the WTO formally acknowledge the flexibilities built into the TRIPS Agreement. Without the background of the case in South Africa, an observer might wonder why it may have been considered necessary to restate rules that already existed ${ }^{8}$. It was because these rules had been misrepresented by a very powerful industry with the backing of key governments, and because the WTO senior leadership stood by the conventional wisdom that the WTO is a Memberdriven organisation for which the executive leadership could not speak. Because the originator companies were misrepresenting the WTO rules to the material detriment of public health, and damaging the WTO as an institution, this was a situation in which the directorgeneral should have publicly reacted ${ }^{9}$.

This may be old history, and I do not recount it in the interests of opening up old wounds. Rather, it is a source of reflection on why it is so difficult to make progress in addressing innovation and access in the field of medicines. There is a great deal of common ground regarding the nature of the public health problems we are facing as a global society and, in particular, regarding the problems we are confronting in terms of treatments and vaccines. When we try to solve these problems, strong differences emerge. History repeats itself in different guises. We remain unable to bridge the divide between different interest groups.

8 Abbott, Frederick M. 'The Doha Declaration on the TRIPS Agreement and Public Health: Lighting Dark Corner at the WTO' in Journal of International Economic Law, vol. 5, p. 469, Oxford University Press, 2002.

The response from autonomy-protective Members may well be, but where does one draw the line? Should the director-general publicly pronounce on controversial subsidies disputes? It is naturally decision-making for the Members. Suffice to say the South Africa case involved a nation at risk of public health cotaclysm, and an unwarranted legal dispute was tying up critical South African government attention and resources. This was not a situation that required, or justified, slowly parsing the subtleties of law. At the very least, one may suggest a 'South Africa case-type exception' for future WTO directors-general.

\section{THE TRIPS AGREEMENT AND FUTURE CHALLENGES}

The major challenges ahead involve the development of new drugs 1 and vaccines, and putting into place mechanisms to allow their wide-scale distribution, including to those with limited financial resources $^{10}$. This is a multidimensional set of tasks. A number of the moving parts bear only a tangential relationship to intellectual property (IP) protection ${ }^{11}$.

\section{A. The critical role of essential medicines}

U ${ }^{\mathrm{HO}}$ recommends a list of essential medicines for treating a substantial proportion of diseases commonly affecting individuals with limited resources ${ }^{12}$. Most of these essential medicines are not protected by patent. Within the class of unpatented or generic drugs, those of certain producers may be protected by brand names or trademarks, and this may modestly increase their price. Nevertheless, because generic alternatives should be available for these drugs, IP typically will not be an issue for many of the essential medicines.

To be clear, the list of essential medicines includes a number of patented drugs that are relatively costly - particularly second-line treatment for HIV/AIDS - and the list is prepared with budgetary

10 Medicines subject matter can be organised along different lines. There are diagnostics, vaccines and therapeutic treatments, each performing different tasks. Medicines may be categorised in non-transmittrable; and modress: broadly speaking, chronic or acute, transmiltable or diabetes, immune system, intestinal, psychiatric, reproductive etc. See, for example, WHO Model List of Essential Medicines, 17th List (March 2011). Available at http://whqlibdoc.who.int/ hq/2011/a95053_eng.pdf. Recently, diseases have been categorised at WHO in accordance with their propensity to affect populations in different economic classes or geographic areas, i.e.: Type I diseases affecting individuals in developed and developing countries, with large numbers of vulnerable people in each; Type II diseases affecting individuals in developed and developing countries, but with more substantial prevalence in developing countries; Type III diseases affecting almost exclusively developing countries. See Commission on Intellectual Property Rights, Innovation and Public Health. Public health, innovation and intellectual property rights: Report of the Commission on Intellectual Property Rights, Innovation and Public Health. WHO, 2006. [hereinafter Commission on IPRs], at 12, citing Macroeconomics and Health: Investing in Health fo 11 For an earlier work on this theme, see Abbott, Frederick M. 'Managing the Hydra: The Hercule Task of Ensuring Access to Essential Medicines' in Maskus, K. and Reichme J. (eds) Interculea Public Goods and Transfer of Technology After TRIPS, p. 393, Cambridge University Press, 2005. 12 See 'Essential Medicines and Pharmaceutical Policies' at www who int/medicines/en: and WHO Model List of Essential Medicines, 17th List (March 2011). Available at http://whqlibdoc.who.int/ hq/2011/a95053_eng.pdf 
considerations in mind ${ }^{13}$, thereby excluding some drugs that might otherwise be listed. We will return to the issue of patented essential medicines later in this paper.

\section{B. Patents remain an issue}

$\mathrm{P}$

atent protection becomes an issue with respect to treatments and vaccines when these medicines are relatively new, and when the new treatment is significantly unique in its efficacy ${ }^{14}$. Many newer patented drugs are substantially similar to existing treatments and may represent only a minor improvement in efficacy, a modification in dosage regime, and sometimes no improvement ${ }^{15}$. While it may be helpful to have lower-priced versions of all new drugs and vaccines, it is probably not necessary to make such new versions available for many situations.

However, there are a good number of newer patented medicines that are currently priced outside the reach of a large part of the world's population, and it is reasonable to expect that new medicines that are a substantial improvement over existing ones will be developed and patented. At present, there are a number of newer treatments for HIV/AIDS, cancer, coronary disease, diabetes, arthritis and joint disease, blood diseases and so forth that are patented and costly ${ }^{16}$. Certainly, in some cases, production costs alone may preclude supplying these drugs to larger parts of the world's population. In India, for example, where the generic industry has been able to supply almost

13 A recent WHO publication references an evolution in the way that budgetary considerations are taken into account:

the 1977 selection criteria put the emphasis on the need to select low-priced medicines. Today the main criterion for deciding if a medicine is essential is effectiveness. Therefore, the high cost of an effective medicine is not a reason for excluding it. The $\mathrm{WHO}$ application procedure requires that information on 'comparative cost and cost-effectiveness' are presented 'as a range of cost per routine outcome (e.g. cost per case, cost per cure, cost per month of treatment, cost per case prevented, cost per clinical event prevented, or, if possible and relevant, cost per quality-adjusted life year gained'. The cost of a treatment course can be considered. For example, a shorter course using a more expensive medicine may be costeffective. Cost can also be a factor when selecting medicines within a therapeutic class to identify the best value for money, recognizing that other products are equal in efficacy."

. P. 4, WHO, 2011

Policy. Ch. 2, 2009 [hereinafter

5 See Angell, Marcia. The Truth About the Drug Companies: How They Deceive Us and What to Do

16 See, e.g., 'Top 200 Prescription Medicines by Sales' in MedAdNews, vol. 30, no. 7, July 2011. all drugs off patent, there remain large sections of the population without adequate access to medicines ${ }^{17}$.

How much of the world's population would have access to a wider selection of vaccines and treatments in the absence of patent barriers is not clear. The United Nations General Assembly recently convened a special session on non-communicable diseases (NCDs) that calls upon WHO to prepare reports on disease burdens, treatment needs and potential solutions ${ }^{18}$.

\section{TRIPS and patents}

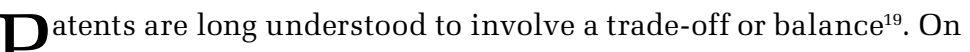
1 one hand, the prospective grant of an exclusive right to control the exploitation of an invention is designed to stimulate the research, development and commercialisation of new and better products and processes. On the other hand, the grant of patent exclusivity permits pricing above normal competitive market pricing because patents forestall entry by potential competitors. Supply and demand for products, including medicines, is a function of a number of factors, and is influenced by the availability of substitutes. When a new medicine represents a major advance in treatment such that the range of effective substitutes is limited, it is possible for a supplier to charge a relatively high price because there may not be an alternative for the patient. The supplier may consider the high price justified in the context of its overall business model. For the patient or government health service unable to afford the price, the limitation on access is a public health problem. This, in a nutshell, is the central conundrum of the TRIPS Agreement and access to medicines debate ${ }^{20}$.
17 See Chaudhuri, Sudip, Park, Chan and Gopakumar, K.M. in Bharadwaj, K. (ed.) Five Years into the Product Patent Regime: India's Response. UNDP, 2010.

18 See 'Political Declaration of the High-level Meeting of the General Assembly on the Prevention and Control of Non-communicable Diseases', Sixty-sixth session, Agenda item 117, Follow-up to the Avane of the Millennium Sunmit.

A

The

20 Cf Maskus, Keith E and Reichman, Jerome $H$ 'The Globalization of Private Knowless, 1956. and the Privatization of Global Public Goods' in Journal of International Economic Law, vol. 7 p. p. 279, Oxford University Press, 2004 
The TRIPS Agreement, as confirmed by the Doha Declaration, incorporates flexibilities with regard to the implementation of patent protection. Governments may, for example, define the criteria of patentability in ways that emphasise the importance of meaningful innovation, authorise exceptions to patent exclusivity - such as to permit third-party activities reasonably related to governmenta submissions - allow experimental use, permit parallel importation and take action against anticompetitive practices in licensing.

The most direct way for governments to override patents in the public interest is through the grant of government use and/or compulsory licences. The TRIPS Agreement, as confirmed by the Doha Declaration, allows the grant of such licences to treat all forms of disease. Governments have been reluctant to undertake government use and/or compulsory licensing for fear of trade retaliation or other adverse economic consequences from the countries that are home to the major originator companies. But, even assuming that governments were willing to override patents, it would still be necessary to provide the funds needed to produce and/or acquire and distribute medicines. Medicines produced under compulsory and/or government-use licence are not free.

Medicines developed under government subsidy might be provided absent patent protection ${ }^{21}$

21 The mechanisms for aggregating investment capital are generally well known. Governments aggregate capital by collecting taxes, developing and selling assets, issuing debt or functioning as The most common mechanism is the subsidisation of research institutions, either public or private (or a combination of both). Another form of government support that has recently received attention is the creation of prize funds that serve as an ex post facto subsidy for the successful researcher. See generally Nordhaus, William. Invention, Growth, and Welfare: A Theoretical Treatment Of Technological Change. MIT, 1969.

A government may use the results of R\&D in its own production and distribution system, such as through a public manufacturing facility and public dispensaries. Or, a government may make the results of R\&D available to private sector enterprises that will seek to profit from its exploitation. The willingness of private sector enterprises to invest in manufacturing and distribution is dependant on their ability to turn a profit, and the ability to turn a profit may depend on the extent to which competitors drive prices towards marginal cost. In this respect, to ensure that private enterprises take up manufacturing and distribution, governments may limit the number of potential competitors,
such as through licensing restrictions. While the TRIPS Agreement mandates

作 or foundation may establish a prize fund under which persons submitting award claims must agree that their research efforts will not be patented. The TRIPS Agreement does not mandate that persons
Nonetheless, major private sector originator companies, and a myriad of smaller research companies developing drugs to license to the major originators, currently depend on patents to protect investments in $R \& D$ and to allow them to secure an adequate risk-adjusted return ${ }^{22}$. Under a regime of compulsory licensing, the research mission of these companies may be inhibited, unless that compulsory licensing regime was designed to provide sufficient returns on investment.

The TRIPS Agreement allows governments to issue compulsory licences while paying adequate remuneration to the patent owner according to the circumstances of each case. On 30 August 2003, following protracted negotiations based on Paragraph 6 of the Doha Declaration, WTO Members adopted a waiver decision - and, subsequently, a protocol of amendment - authorising "predominant" exports under compulsory licence, further extending the potential range of supply under government use/compulsory licensing ${ }^{23}$. Least-developed countries, until at least 1 January 2016, are required neither to implement pharmaceutical patent protection or regulatory data protection, nor to enforce such protections should they already be legislated. In this respect, it is unclear whether, as a strictly legal matter, the TRIPS Agreement stands in the way of allowing governments to pursue the

for innovation-incentive models that do not rely on the 20-year minimum patent term that must be available under domestic law. It does not mandate a single innovation model. Private foundations may also provide capital for R\&D and largely function within the same decision-making parameters as governments (although this may depend on the particular tax environment in which a foundation
operates).

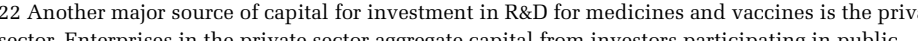
markets (by issuing equity and debt) or otherwise by soliciting investments from investors in private markets. Investors in private sector companies typically seek a profitable return on capital; they expect the businesses they invest in to increase their wealth. When a private sector company invests in medicines-related R\&D, it does so with the expectation of selling or licensing a newly developed
in product, or process, for a profit so that it can repay the invested capital plus incremental gains. This is where intellectual property (IP) protection enters the picture. Drugs and vaccines are generally subject to reverse engineering and may be reproduced by potential competitors once they have been made publicly available. If the barriers to entry into the market are low, competitors will drive prices towards the marginal cost of production. Marginal cost pricing does not permit the company that invested in R\&D to recapture its investment, and return a risk-adjusted profit. In order to address a foreseeable shorffall in investment in R\&D, governments have provided protection in the form of patents and marketing exclusivity in an effort to allow private sector investors to secure sufficiently
profitable returns.

WT/L/641, 8 Decor the TRIPS Agreement'. WTO General Council, Decision of 6 December 2005 negotiating history and text of the 30 August 2003 waiver decision, which forms the basis of the amendment, see Abbott, Frederick M. 'The WTO Medicines Decision: World Pharmaceutical Trade and the Protection of Public Health' in American Journal of International Law, vol. 99, p. 317, 2005. 
comprehensive provision of medicines. Arguably, it is more a political matter that governments choose not to pursue the comprehensive supply of medicines. The political problem is twofold.

D. The political and budgetary dimensions

eveloping country governments do not make use of government use and/or compulsory licences because of the threat of economic retaliation from countries where the originator pharmaceutical companies are based. This type of threat was clearly evidenced in recent years when Thailand issued government use licences for medicines to treat HIV/AIDS and coronary disease, and the European Commission strongly objected ${ }^{24}$. In this case, the TRIPS Agreement manifestly permitted the government of Thailand to issue licences, and the European Union (EU) reaction was political (and threatening) ${ }^{25}$. This is not so dissimilar to the situation in South Africa in the late 1990s.

Moreover, when governments of developing countries have used other TRIPS Agreement flexibilities to promote access to medicines, such as by defining the criteria of patentability so as to require significant therapeutic innovation, they have similarly been subjected to overt challenge from OECD private sector enterprises ${ }^{26}$, and more subtle diplomatic pressure from their governments ${ }^{27}$. (Least-developed countries are somewhat less likely to be the subject of intensive pressures, mainly because market opportunities in these countries are

24 Former EU Trade Commissioner, Peter Mandelson, in addition to suggesting that future foreign investment in Thailand would be restricted, argued that "Neither the TRIPS Agreement wherever medicines exceed certain prices" This was an odd of applying compulsory licences wherever medicines exceed certain prices". This was an odd argument coming from an EU Trade
Commissioner on at least three counts. Firstly, Member States of the European Union routinely control medicines prices and do not allow them to exceed certain levels. Secondly, the Doha Declaration expressly provides that WTO Members "affirm that the Agreement can and should be interpreted and implemented in a manner supportive of WTO Members' right to protect public health and, in particular, to promote access to medicines for all", and the Declaration does not imply any restriction on the systematic granting of compulsory licences to achieve that end. Thirdly, the government of Thailand had not announced a programme of systematically granting compulsory icences. Specifically, it had granted three. See Abbott \& Reichman, supra note 3, at 952-57. The US government also raised concerns regarding the licences granted by Thailand, but at least, in the 25 See Abbott \& Reichman, supra note 3, at 949-57.

26 A notable case in point is the private action pursued in India seeking to overturn Section 3(d) of he amended Patent Act (2005). See Novartis versus Union of India, High Court of Medro, W.P. Nos. 24759 and 24760 of 2006. 27 The government of Switzerland did not support its private actor in challenging Section 3(d) of 12 India's Patent Act, but other OECD governments have raised this matter with the Indian government. substantially less material to patent-owning enterprises. This has facilitated the supply of HIV/AIDS and other medicines by OECDbased procurement groups, including pursuant to the extensions established under Paragraph 7 of the Doha Declaration.)

The second part of the political problem is internal to developing countries. Given scarce resources (a situation that affects government at all levels of development), are governments willing to make a commitment to a comprehensive supply of medicines to the public? Are governments willing to limit military expenditure in order to provide financial support to public health? For a significant number of developing countries, it is unrealistic, at the present time, to suggest that governments can ensure a comprehensive supply of medicines, even at generic prices.

Budgetary limitations in all countries place pressure on multinational originator pharmaceutical companies to reduce prices. As a practical matter, price control regimes serve similar functions to compulsory licensing by securing a supply of medicines at a not-toexceed price, and may be considered a less intrusive alternative than compulsory licensing ${ }^{28}$. As noted with regard to the merits of the case brought against the government of South Africa, the TRIPS Agreement does not address or inhibit the operation of price control regimes. In Europe, governments routinely intervene to control prices, resulting in originator drugs being sold in Europe for half the price they are sold in the United States. Other OECD countries also control prices and reimbursement allowances. Developing countries also employ price controls, though perhaps not as commonly as they could.

The TRIPS Agreement may provide the flexibility for governments to act in a variety of different ways to promote affordable access to medicines, and the Doha Declaration may have reinforced the meaning of the terms of the TRIPS Agreement, but it has not transformed the political dimension. This is not to suggest, for example, that facile compulsory licensing is the solution to the world's medicines supply problems, but merely to point out that statements regarding the 
flexibilities in the TRIPS Agreement cannot be taken at face value. Intellectual property policy remains highly politicised ${ }^{29}$.

There is an inherent logic in the position of the OECD governments and originator companies ${ }^{30}$, and there is a reasonable justification for developing countries and their local industries to oppose that logic. The consequence is a continuing struggle for an equilibrium point at which the originator multinational companies are earning an adequate return on investment while developing countries have access to medicines at prices that are reasonably affordable.

\section{TRENDS FOR THE DECADE}

Tn considering the role of the multilateral institutions for the coming decade, it is first worth identifying some major trends influencing the global medicines supply system, with an emphasis on the role of intellectual property protection.

$\rightarrow 1$. Negotiation of intellectual property norms affecting trade in pharmaceuticals has shifted to bilateral and regional settings. Trade ministries have shifted the focus of their attention to these minilateral setting ${ }^{31}$. While this trend has been evident since the late 1990s, the apparent failure of the Doha Development Round negotiations at the WTO has reinforced it.

It must also be recalled that major developments in the field of pharmaceutical-

29 The Doha Declaration did little to alter the fundamental character of the global pharmaceutical supply sector that relies on a small number of multinational originator companies to devaceutic commercialise new drugs and vaccines, secure patents and marketing exclusivity rights, and to rely on the governments of the countries in which they are based to protect their mercantile interests in on the governments of the countries in which they are based to protect their mercantile interests in
export and foreign direct investment markets. Pharmaceutical manufacturers based in developing countries produce and distribute drugs that are not protected by patents or marketing exclusivity rights in relevant markets. They have not yet become a significant factor in the development of new drugs and vaccines, although they have continued to advance production process technologies. 30 OECD governments have both mercantile and public health policy grounds for seeking to deter government use/compulsory licensing. From a mercantile perspective, the royalty inflows from government use/compulsory licensing are expected to be substantially less than the imputed royalty inflows from sales of patent-protected/marketing-exclusivity-protected drug sales. From a public health policy perspective, the reduced royalty lows will result in a lower level of investment in

31 See generally Crawford, Jo-Ann and Fiorentino, Roberto V. The Changing Landscape of Regional and Reichenmiller, Patrick. Tightening TRIPS. The Intellectual Property Provisions of Recent US related IP and regulatory rule-making take place at national level (including at EU level), and that this rule-making has the most direct impact on the production and distribution of medicines.

$\rightarrow$ 2. Major emerging market countries such as Brazil, China and India have assumed greater importance in the strategic planning of the major originator pharmaceutical companies, and competition for and in those markets is increasing ${ }^{32}$. As a result, more attention will be paid to legal developments in these countries, including IP and regulatory enforcement.

$\rightarrow 3$. As a current generation of originator industry patents is at or near expiration (the so-called 'patent cliff'), competition between the branded generics of the originator companies and the generic products of other manufacturers is becoming a more significant factor in industry strategy. This change in the competitive environment will affect both developed and developing country markets, including through mergers and acquisitions intended to improve positions in the generics marketplace ${ }^{33}$

$\rightarrow 4$. The focus of $R \& D$ is shifting from small-molecule chemistry to large-molecule/ biological materials engineering. This is necessitating the adaptation of the regulatory environment, as it concerns both intellectual property and medicines regulatory matters ${ }^{34}$. Manufacturers in developed and developing countries are shifting their focus towards biologics, as markets for these products are less saturated than markets for small-molecule products.

$\rightarrow 5$. R\&D on new drugs and vaccines is becoming more geographically distributed as a consequence of evolving information technologies, and as multinational originator companies expand their presence in emerging economies ${ }^{35}$.

$\rightarrow 6$. Information technologies are playing an increasingly significant role in R\&D as the focus is shifting from physical products to data mining and modelling ${ }^{36}$. There are a considerable number of critical IP issues arising from the bioinformatics revolution that have yet to be seriously addressed.

$\rightarrow 7$. As the major multinational originator companies have cut back on research

32 See Trends in Local Production of Medicines and Related Technology Transfer. Prepared for the WHO Department of Public Health, Innovation and Intellectual Property by Frederick M. Abbott. WHO, 2011 33 Idem

See Dukes, M.N.G. Biotechnology Regulation in the Health Sector. OECD International Futures Project on "The Bioeconomy to 2030: Designing a Policy Agenda". January 2008. See, e.g. ovartis Media Release: Novartis inaugurates large-scale US based cell-culture influenza vaccin A

or pharmaceutical industry executives conducted in connection with research for WHO project on local production of medicines, 2009-2010. 36 See, e.g., Jones, Phillip B.C. 'The commercialization of bioinformatics' in Electronic Journal of Biotechnology, vol. 3, no. 2, issue of 15 August 2000.

Available at http://eib.ucv.cl/content/vol3/issue2/full/4/bip/index html 
targets and as innovation rates have slowed ${ }^{37}$, some governmental authorities (and particularly the US National Institutes of Health) are assuming a more active role in $R \& D^{38}$. As potential cost savings from moving $R \& D$ into the public arena emerge, and as national budgets continue to be stressed, it is possible that governments will become more active in the downstream production and supply of medicines.

$\rightarrow$ 8. The US financial crisis of 2008-2009 and the present financial crisis in the European Union are resulting in large-scale cutbacks in government expenditure, including foreign aid ${ }^{39}$. The time-frame for recovery is difficult to predict, but it is likely that the next decade will be characterised by restrained government spending. As a consequence, government-funded programmes such as the Global Fund and PEPFAR are likely to come under pressure. Developing countries may need to reduce reliance on foreign contributions as a source of funding for medicines purchasing

The trends identified above are largely beyond the control of any government or multilateral institution. They reflect the consequences of scientific and economic development. However, multilateral institutions in and outside Geneva will need to address these trends.

\section{SOLUTIONS BASED ON FIRST PRINCIPLES}

The question that all of us face is whether it would be possible to 1 invent a system for the global supply of medicines starting from a set of first principles that would reflect public health needs, while at the same time realistically taking account of the fact that economic circumstances throughout the world are radically divergent ${ }^{40}$. In some

37 U.S. Government Accountability Office. New Drug Development: Science, Business, Regulatory, and Intellectual Property Issues Cited as Hampering Drug Development Efforts. Report to Congressional Requesters, Nov. 2006, GAO-07-49,

38 See Collins, F.S. 'Reengineering translational science: The time is right' in Science Translational Medicine, vol. 3, Issue 90, 90cm17, 201

Available at www.nih.gov/about/director/articles/translational_science_07062011.pdf 9 Myers, Steven Lee. 'Foreign Aid Set to Take a Hit in U.S. Budget Crisis' in The New York Times, 3 October 2011. (The proposals have raised the specter of deep cuts in food and medicine for

theen the way the development and distribution of medicines is viewed .

th perspective might suggest a set of priorities along the following lines: countries, average income per capita is approximately USD 40,000 per year, while in others, average income per capita is about USD 400 per year ${ }^{41}$. It is unrealistic for the designers of a system starting from first principles to predicate a global redistribution or equalisation of wealth. Human civilisation as portrayed in the Star Trek series appears to have done away with wealth as a social determinant, but until we reach the relevant 'star date', it is reasonable to assume that wealth will remain important. Even assuming per capita income levels in the emerging markets of Brazil, China, India and South Africa begin to approximate those of the OECD countries, this will still leave large differences in the global distribution of wealth.

What could we envisage as a system based on first principles?

$\rightarrow 1$. All people would be entitled to a baseline standard of access to medicines based on the essential medicines concept pioneered at WHO.

$\rightarrow$ 2. All governments would be able to provide - or ensure the provision of - more advanced medicines within the reasonable budgetary capacity of the nation.

$\rightarrow$ 3. Sufficient financial incentive would be available to ensure that funds are invested in R\&D on new drugs and vaccines, either through government funding or private sector initiative.

$\rightarrow 4$. The prescribing of drugs and vaccines would be based on the best interests of the patient and not on the commercial interests of medicines suppliers.

$\rightarrow 5$. Adequate regulation and enforcement would be undertaken to ensure that medicines are of the necessary quality and safety.

distribute medicines without regard to ability to pay, or social standing

develop therapies that are reasonably easy for patients to follow

- focus on prevention and lower-cost solutions (including va

minimise adverse side effects to protect patient health

A cont use of medicines to situations of na

- concentrate Rad efforts on chronic diseases prevalont in high-income areas

sell medicines to maximise profitability, taking into account supply and dema

encourage use of medicines, particularly newer, more expensive one

.

For those pars of there are a range of terser

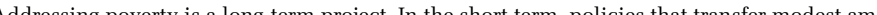

f wealth from affluent arees of the world to those less afluent are required. See e. Report of the Commission on Macroeconomics and Health. Macroeconomics and Health: Investing in Health for Economic Development, WHO, 2001.

Available at http://whqlibdoc. who.int/publications/2001/924154550X.pd 


\section{A. Essential medicines plus}

Tn terms of ensuring access to essential medicines for all people, 1 this is mainly a question of finance and distribution. Essential medicines already exist and are selected with budgetary considerations in mind ${ }^{42}$. It would not be so difficult for all governments to agree to a proportional contribution - based on national GDP per capita or a similar index - to a central fund administered by the World Bank or other institution to make available such medicines, purchased through open global public tender or other mechanism. The more costly medicines on the essential medicines list relate predominantly to the treatment of HIV/AIDS. The Global Fund and other financing mechanisms - such as UNITAID and PEPFAR - have already been established to address global requirements for HIV/AIDS treatments ${ }^{43}$ Creating a more broadly attentive international mechanism for the guaranteed procurement and distribution of essential medicines should be well within the cooperative capacity of governments and industry, without any radical transformation of the international economic framework. Details, such as establishing regional or geographic bidding and supply quotas so as to reasonably allocate economic opportunity among suppliers, could be worked out.

The Medicines Patent Pool (MPP) has captured one important element of improving the supply of essential medicines to treat HIV/ AIDS, and potentially other diseases affecting developing countries, when more advanced treatments are required (such as second-line antiretrovirals) $^{44}$. The MPP is an important initiative for extending the availability of treatments under patent to lower-income individuals. The MPP framework could be extended and integrated with the international financing mechanism(s) to ensure affordable access for essential medicines under patent ${ }^{45}$.

42 See note 12, supra.

43 See, e.g., Global Fund. Guide to the Global Fund's Policies on Procurement and Supply Management. 2004. Available at www.who.int/hdp/publications/13h.pdf; PEPFAR press release: Use of Generic Antiretroviral Drugs and Cost Savings in U.S. HIV Treatment Programs, 18 July 2010 ADS Project' Available at wwwunitaid ew/en/secondline html. Concerns remain regarding the All patents in producing countries.

44 See Medicines Patent Pool at www.medicinespatentpool.or
B. Advanced treatment opportunity

ach government should have the autonomy to make available more Uadvanced drugs and vaccines for the national population, even if those drugs and vaccines are not classed as essential medicines. This must necessarily take into account the reasonable budgetary situation within each country, and should be based on the fair treatment of non-national developers of treatments and vaccines ${ }^{46}$. This is more complex than addressing the supply of essential medicines, most of which are not under patent. The system should reasonably take into account the risk-adjusted cost associated with the development of medicines. Ideally, it would be possible to identify and account for the R\&D costs associated with each new medicine in order to determine a level of fair compensation for the developer ${ }^{47}$. Governments and/or private sector buyers within each country could elect either to purchase from the developer of a new drug at the fair compensation price, or produce/import from an alternative supplier upon payment of a fair royalty to the developer ${ }^{48}$.Private sector actors would control their offerings at fair compensation, and alternative suppliers could bid on providing comparable products, including payment of a fair royalty. The government or other purchaser would choose among the competing offers, with the final amount of the royalty due to the originator being subject to submission to international arbitration.

the next section is relevant

46 The access problew, while self-evidently most serious in poorer developing nonetheless affects relatively affluent nations as well. Recent reports from the United States point to waiting lists for HIV/AIDS treatments among those dependant on government programmes. (See ADAP Advocacy Association, 2010 Annual Report: "The ADAP Advocacy Association (aaa+) concluded another productive year in 2010, despite the backdrop of the escalating waiting lists under the AIDS Drug Assistance Programs ('ADAPs') nationally reaching historic levels... Last year from January to December, ADAP waiting lists increased by over 1,500\% from 361 individuals in nine states to just shy of 5,000 individuals in ten states.") Senior citizens in developed countries may lack the financial resources even for relatively modest co-payments to obtain necessary

medicines.

47 At this stage of presenting the text proposal, the author does not address whether the entitlemen to compensation held by the developer of the new drug or vaccine should be based on a patent (as denominated by the present TRIPS and international IP system), or some newly negotiated and denominated entitlement to fair compensation. Working out a new system by which basic Modification of the TRIPS Agreement may be required. This raise the question of the degree of change negotiators can or should be addressing at least in the initial stages. The author has elsewhere suggested the development of 'quasi-patents'. See, e.g., Abbott \& Dukes, Ch. 2, supra note 13 48 The suggestion to request offers from originator companies to supply, with the alternative of compulsory licensing, was made in Abbott \& Reichman, supra note 3, at 973-77. 
The issue of determining fair royalty compensation is a sensitive one. Determinations might, preferably, be made by a body of neutral arbitrators operating under a set of guidelines established through multilateral negotiation. Such a body of neutral arbitrators could be established under the aegis of an existing multilateral institution, or it could be established as an independent international body. The timing of compensation determinations would be important, since final determinations on royalties would affect the revenue streams of medicines developers and suppliers. However, some multilaterally negotiated minimum royalty would be payable by third-party suppliers under agreed guidelines, leaving only adjustment amounts for after-the-fact submission and determination.

Up until now, multinational originator companies have been reluctant to make data on R\&D costs publicly available. The reasons for such reluctance are not entirely clear, but may include concerns regarding the provision of confidential, commercially valuable data to competitors. In this respect, it may be possible to design a fair compensation body that would operate under appropriate confidentiality constraints with regard to commercially valuable information.

Determining a level of fair compensation would, ideally, reflect the importing or producing country's ability to pay. The level of royalty might, therefore, reasonably take into account the level of lost opportunity cost for the originator company that developed a new drug or treatment. Countries at a lower level of economic development (e.g., with a lower per capita GDP) are likely to be less attractive markets in terms of volume of sales, and the opportunity cost of not supplying such markets will be lower than for more economically developed countries.

The objective of this proposal is to provide a sufficient level of commercial opportunity to incentivise the private sector to develop and supply new medicines. The underlying thesis is that financial opportunities would not be significantly restricted under this alternative arrangement, but may even expand as the range of royalty payer or buyers increases. Although this proposal sounds complex, once a modicum of practice has developed, determinations could become fairly routine and predictable.

There are a variety of potential variations on the foregoing theme, including keeping the entire process within individual national legal systems. The essence of the idea is to move from a system in which originators/patent holders are able to block the third-party supply of drugs and vaccines, to one in which there are potential multiple suppliers, with a remedy of fair compensation to the originator based on R\&D costs and taking into account the ability of purchasers to pay.

As an arrangement involving determinations by international arbitrators, the proposal is largely consistent with the present text of the TRIPS Agreement. However, a comprehensive central system of neutral arbitration regarding remuneration that is not appealable within domestic legal systems, as well as certain other elements, could cause some interpretative difficulties. It may be that a multilateral agreement adopting and enabling this proposal based on first principles would entail some modification of TRIPS Agreement rules. The design of an international medicines supply system based on first principles might predictably require some modification of existing rules, and the foregoing proposal was not suggested on the basis of its TRIPS-compatibility.

Nonetheless, differences with the present international IP system should not be exaggerated. The international patent system, as reflected in the TRIPS Agreement, provides patent owners with the right to prevent others from making, using, offering for sale, selling or importing, for those purposes, their products. The United States Supreme Court in eBay versus MercExchange distinguished the rights of the patent holder from the remedy for infringement ${ }^{49}$. The TRIPS Agreement requires that courts and administrative bodies have the authority to issue injunctions to prevent future patent infringements, but it does not mandate the issuing of injunctions. Instead, a reasonable remedy may include 
the payment of fair compensation in the form of a royalty. (In fact, this optionality is the confirmed rule in the United States following the eBay case.) Establishing an international medicines supply mechanism based on fair compensation is not a departure from concepts embodied in the TRIPS Agreement, and it is consistent with the Doha Declaration mandate to promote access to medicines for all.

\section{Continuous stream of innovation}

The most fundamental problems of medicines are scientific ${ }^{50}$.We 1 do not have robust vaccines or cures for asthma, cancer, coronary disease, diabetes, joint disease, HIV/AIDS, psychiatric disorders, tuberculosis and a variety of infectious diseases. However, we do have reasonable belief that our understanding of the causes of disease is improving and that, as it does, the identification of mechanisms for addressing the causes will improve. How can the international community best translate scientific advance into new drugs and vaccines? ${ }^{51}$

50 The first-best solution to global disease burdens would be accessible vaccines to prevent them, or accessible treatments to cure them. Were real life to replicate science fiction movies, benign visitors from outer space would arrive and unlock the secrets of human biology, ending disease and associated suffering in a flash. The human race, however, appears for the time being to be reliant on Bill and Melinda Gates, Warren Buffett, and the National Institutes of Health to provide the funding for R\&D that may slowly unravel the mysteries of disease. As the recent death of Steve Jobs from pancreatic cancer reminds us, even the best, brightest and wealthiest among us do not yet have access to freedom from disease and death.

51 The governments of developed and emerging market economy countries are experimenting with rules to promote innovation and encourage access to medicines. The United States Congress has other approaches to promoting innovation. The National Institutes of Health has entered a new where focus is increased on transforming basic research into treatments through the establishment of NCATS. The US Supreme Court has encouraged the use of research exceptions. (See Merck KGaA versus Integra LifeSciences, case reference 545 U.S. 193 (2005). S Switzerland has also adopted rules promoting experimentation in biotechnological sciences. (See Articles 9 and 40 (b) of the Swiss promoting experimentation in biotechnological sciences. (See Articles 9 and 40 (b) of the Swis Directorate has closely examined the adverse effects that poor patenting practices may have on access to generic drugs. (See European Commission Competition Directorate, Pharmaceutical Sector Inquiry: Final Report (8 July, 2009).)

Brazil, China and India are each charting their own path towards an innovation policy within the framework established by the TRIPS Agreement, but encouraging national perspectives. As thes countries continue to build up their R\&D infrastructures, from a public health standpoint it is important that sufficient attention be paid to diseases affecting the local population, including thos on the lower levels of the economic hierarchy. Furthermore, as the drive to achieve commercial well-off remain. (See, e.g. '200 years of Intellectual Property in Brazil'. Seminar on Intellectual Property as an Instrument of Industrial Policy: Lessons and Challenges, Brazil Ministry of Externat Relations, in partnership with WIPO, the Alexandre de Gusmão Foundation (FUNAG) and the National Institute of Industrial Property (INPI), Brasilia, 29-30 April 2009; EU-China IPR2 Project. Third Revision of China's Patent Law. Available at www.ipr2.org/images/eu patent law-final.
The present system is largely based on competition among private sector actors seeking to capitalise on their achievements. The present system has the clear advantage of motivating individuals and companies to work hard to achieve commercial success $^{52}$. It is also well recognised that this system introduces certain distortions - vis-à-vis conceptually ideal public health outcomes - because it encourages the development and marketing of products with the greatest potential for economic return, as opposed to the development of products with the maximum public health benefit (recognising that, in some cases, these objectives will overlap). The typical closed-source model of drug $R \& D$ posits the secrecy of information as the means to achieve commercial success.

Just as enterprises involved in the information technology sector recognise that advances may be achieved through opensource development, there is also some movement to encourage open-source sharing of information and research in the development of new drugs and vaccines. As with the open-source software movement, the question that is naturally asked is, 'What incentive may there be for R\&D without patenting and selling new drugs at premium prices?'. The open-source software movement has succeeded beyond some expectations for a variety of reasons, but it is not clear to what extent the factors that motivate opensource software development can be transposed to the medicines sector. The open-source software sector allows enterprises to commercialise products by tailoring them to specific clients, generating service revenues. The open-source software sector has relatively low upfront costs of programming. Clinical trials of new drugs and vaccines are expensive and risky, and some party must bear the long-term risk of liability for adverse reactions from drugs that have been commercially marketed. It is certainly conceivable that elements of the open-source movemen can inform the development of new drugs and vaccines, but using 
open source as the basis for new drug development will require tailoring a mechanism to move research into clinical development and distribution. It is certainly conceivable that end users such as government health systems, hospitals, pharmaceutical benefit providers and other downstream drug purchasers might see advantages in contributing to the later-stage drug development of open-source innovations in exchange for reduced purchasing costs.

It is commonly recognised that the patent system does not incentivise R\&D for diseases that only affect very poor populations (neglected or Type III diseases). ${ }^{53} \mathrm{~A}$ number of policy approaches have been adopted to address this problem, including through the establishment of public development partnerships (PDPs), advanced purchase commitment arrangements, and the direct subsidisation of research. PDPs have adopted distribution models that differentiate between geographic markets (e.g., developed and developing), as well as between purchaser characteristics (e.g., public and private market). These efforts are bearing fruit, but PDPs are dependant on contributions and face the challenge of sustainability as donor priorities may shift.

One promising development is the new approach being taken by the US National Institutes of Health in establishing its National Center for Advancing Translational Sciences (NCATS). The basic idea is to advance its role in new drug development beyond basic research and into the later stages of drug development, closer to marketing approval. This approach is attempting to redress the shortfall in genuine innovation over the past decade. ${ }^{54}$

A proposal has been submitted to the WHO expert working group on R\&D financing ${ }^{55}$ to negotiate an international agreement on new drug R\&D. ${ }^{56}$ While the details of the proposal appear to be in the early

53 See Commission on IPRs, supra note 9.

54 See also option of transterable approval vouchers e.g., US Food, Drug and Cosmetic Act (FDCA), sec. 524. [21 USC \$360n] 'Priority Review to Encourage Treatments for Tropical Diseases', and Purchase Agreements For Low-Income Countries: Practical Issues' in Health Affairs, 24, no. 3, 653-665, 2005.

55 Consultative Expert Working Group on Research and Development: Financing and Coordination (CEWG). See www.who.int/phi/news/cewg_2011/en/index.html stages, the idea of organising negotiations on new ideas for promoting $R \& D$ is in itself of value.

It may well be that no single solution to the problem of encouraging R\&D on new drugs and diseases is necessary or appropriate. It is certainly possible for competing systems of innovation to exist and thrive.

D. Rational prescribing

7 he supply of medicines has become a commercial enterprise 1 subject to the typical demands of the marketplace. It is a paradox of the medicines supply system that profitability for the suppliers depends on increased consumption by patients. Yet there are few, if any, medicines that do not carry risk, and we are often uninformed about long-term risks because of inherent limitations in drug approval processes. The TRIPS Agreement and the Doha Declaration did not include the issue of rational prescribing among their themes, partly because the TRIPS Agreement is embedded in the constellation of WTO agreements designed to promote trade and economic activity. In most areas of trade, more is better. In the prescribing of medicines, this is not necessarily so. Whatever systemic changes are made to the international supply system for medicines, attention should always focus on limiting incentives for the consumption of medicines for the sake of commercial success. The focus must be on the best interests of the patient.

\section{E. Quality, safety and efficacy}

The international system for the supply of drugs and vaccines must ensure that patients receive products of appropriate quality and safety. This is something that is reasonably within the control of regulators, producers and distributors. We expect the developers of new drugs to seek efficacious results and we expect regulators to assess efficacy objectively. 
Officials responsible for overseeing the production and distribution of medicines are in an unenviable position. Resources for inspections are limited. Unscrupulous operators seek to circumvent regulatory mechanisms. Legitimate producers do not want unnecessary interference with their supply chains.

Cooperation among regional authorities should be promoted so as to extend capabilities under budgetary restraints. Private sector enterprises should not use rules designed to protect the integrity of the drug supply to secure commercial advantage over legitimate competitors.

\section{THE ROLE OF THE MULTILATERAL INSTITUTIONS}

\section{World Health Organization}

W ${ }^{\mathrm{HO}}$ is a complex organisation functioning both as a headquarters and national/regional support institution. ${ }^{57}$ WHO plays a number of roles: monitoring outbreaks and pathways of diseases, and preparing responses; developing medium- and longer-term strategies for addressing public health, including through the negotiation of international agreements; providing assistance in the implementation of new technologies to create and distribute vaccines and other medicines; and, more recently, acting as a negotiating forum for rules relating to the intersection of public health and intellectual property law. As it attempts to address this broad set of mandates, WHO is facing substantial budgetary pressures.

WHO must continue its core function of strengthening public health systems, including through the identification of essential medicines and providing assistance with acquiring and distributing them to the public. It must also strengthen global capacity for a systemic response to pandemic disease, which it is doing through its support of initiatives for vaccine stockpiling and for spreading production initiatives among developing countries. Among the more promising new initiatives is the proposal for the negotiation of an R\&D treaty within the framework of the expert group on financing innovation. Although the proposal is at the formative stage, the possibility of an open global dialogue regarding the best means for developing new medicines would itself be of substantial value. ${ }^{58}$ WHO should also continue to support the interests of developing countries in enhancing the local production of drugs and vaccines. ${ }^{59}$

\section{World Intellectual Property Organization}

Tn the period since the adoption of the Doha Declaration, WIPO has become significantly more sensitive to issues surrounding access to medicines. ${ }^{60}$ WIPO has assisted with the establishment of patent databases regarding specific drug classes and vaccines, ${ }^{61}$ has worked with the Medicines Patent Pool on the development of appropriate licensing practices, and has launched a database of technologies available for licensing for R\&D on neglected tropical diseases and royalty-free sales in least-developed countries. ${ }^{62}$

58 WHO has already embarked on several major initiatives that include addressing the role of intellectual property in innovation and access. Following through on these initiatives is likely to occupy the better part of a decade. The initiatives include the work programme under the Global Strategy and Plan of Action adopted by the World Health Assembly in 2008. Most recently, WHO has turned to mechanisms for financing treatments for Type II and Type III diseases, having established an expert group to make proposals on this subject. In addition, $\mathrm{WHO}$ is examining its institutional structure. The work of the WHO Consultative Expert Working Group on Research and Developmen
Financing and Coordination (CEWG) (see www.who.int/phi/news/cewg_2011/en/index. html) must necessarily take into account the role of patents and other forms of IP. Patents an related forms of IP reflect rights of ownership and control. When innovation takes place, the

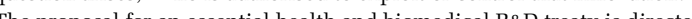

the the price of treatments from R\&D expenditures. It encourages the sharing of research tools and outputs, necessarily entailing consideration of the role of patents and other forms of IP. If negotiations on a WHO R\&D treaty are undertaken, the relationship between R\&D treaty rules and the WTO TRIPS Agreement will need to be examined.

59 The Global Strategy and Plan of Action includes a number of references to facilitating the local production of medicines in developing countries. Assuring a sustainable supply of medicines throughout the developing world could be facilitated by increasing the extent to which production of those medicines is undertaken locally, whether on a national or a regional basis. For local production to be successful in less-developed regions, it is importan that technological inputs be made available and that more attention be focused on all levels of scientific training. The WHO PHI Secelariat, in cooperation with UNCTAD and ICTSD (and with funding from the European Union), recently completed a series of studies regardin

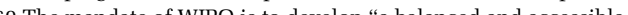

(1) wipo int/patentscope/en/ programs/patent landscapes/pl_about.html.

62 Francis Gurry, director-general of WIPO, describes the objectives: “By joining WIPO 
WIPO is working to assess its technical training programmes, hopefully with a view towards a more holistic approach to the relationship between IP and social welfare interests. A more balanced approach is creating certain difficulties for WIPO as some major IP offices threaten to move patent administration functions away from WIPO. During the coming decade, WIPO faces the challenge of maintaining the delicate balance between appropriately acknowledging the contributions of innovators while, at the same time, addressing the problems of development. ${ }^{63}$

The technical support aspects of WIPO's work should be distinguished from the rules negotiations that are continuing among its Member States. The WIPO Secretariat (or International Bureau) exercises a certain level of autonomy in the day-to-day implementation of its technical work programme and, in the last five years or so, there has been a significant improvement in attention to problems affecting R\&D and access to medicines by the secretariat. Negotiations regarding patent harmonisation among Member States remain contentious. Whether that changes during the next decade may, to a large extent, depend on whether changes in the attitudes towards patents within emerging economy countries are reflected at the level of multilateral negotiations.

Re:Search, companies and researchers commit to making selected intellectual property assets available under royalty-free licenses to qualified researchers anywhere in the world for research an development on neglected tropical diseases, malaria, and tuberculosis. This commitment should Press Release, 26 October 2011 (PR/2011/699): and ind diagnostics for these diseases." Who the wipo.int/research/en. See also Hermann, Rachel Marusak. "WIPO Re:Search Bridges Public, Private Sectors For Neglected Disease Research' in Intellectual Property Watch, 27 October 2011. 63 The Patent Cooperation Treaty (PCT) generally provides a valuable mechanism for patent holder from many countries at different levels of development to more efficiently apply for patents in multiple jurisdictions. However, public health interest groups have questioned whether facilitating pharmaceutical patent applications is appropriate, particularly if the quality of resulting patents granted by national/regional authorities is not high. WIPO and its Members should keep a watchfu eye on how the PCT system affects access to medicines, paying particular attention to developing improved systems for the examination of patent applications with the aim of improving patent quality, recognising that WIPO as an institution does not exercise control over the national/regional innining offices operating within the $P C T$ system. While low-quality patents may act as barriers ${ }^{\circ}$ third parties willing and able to invest the resources required to challenge those patents. In lower income countries, third parties typically lack the financial incentives and resources needed to challenge granted patents. Finally, national/regional patent offices should not be unduly influenced by user demands. Patent examiners act on behalf of the public to maintain an appropriate
World Trade Organization

The WTO promotes liberalised trade among its Member coun1 tries for the purpose of fostering economic growth, employment and social welfare. ${ }^{64}$ In 1995 , rules regarding intellectua property were added to the scope of multilateral trading rules through the WTO TRIPS Agreement. The core function of the TRIPS Agreement was to establish a minimum set of global standards for IP protection to facilitate trading opportunities among countries. The TRIPS Agreement built in flexibilities to allow governments to take measures to protect public health through the use of exceptions to patent rights, government use and compulsory licensing, the development of criteria of patentability, parallel importation and other mechanisms. ${ }^{65}$

The WTO should continue its core function of promoting liberalised trade and serving as a forum for the resolution of disputes. The WTO operates through the participation of trade ministers and ministries. Intellectual property offices are often situated within the trade and/or commerce ministry of government, and are routinely involved in meetings of the TRIPS Council at the WTO. Health ministers and ministries are typically accorded a minor role in the development of trade policy. As a consequence of the WTO's trade mission, it is not a first-best forum for the development and implementation of global health policy. ${ }^{66}$ Nevertheless, WTO rules may serve as a check on mercantile excess as regards trade in pharmaceutical products, for instance,

64 The WTO Agreement in its preamble frames the objective of the institution in terms of sustainably promoting economic development through the reduction of trade barriers. 65 This author recognises that there has been considerable discussion, including in the TRIPS Council, concerning the effectiveness of the 30 August 2003 Waiver Decision and Article 31bis Protocol of Amendment for exports of medicines under compulsory licence. In this author's view, realisation of the potential utility of compulsory licences is mainly a political question, with most governments reluctant to act in the face of political and economic constraints. This author does not suggest that improvements could not be made to the mechanisms available under the TRIPS Agreement and waiver, but unless and until governments demonstrate a willingness to employ these mechanisms, refinement of the mechanisms is probably not the best use of diplomatic energies. WTO Members and their stakeholders should attempt to use the waiver as appropriate to determine whether, in foct
it is usable.

Secrearin Inteltions are not intended to reflect in any way on members of the WTO regarding the relationship between IP rules and public health. These individuals, however do not have the authority to formulate policy on behalf of the Members, and operate under the watchful eye of Member delegates. 
by continuing to recognise the importance of freedom of transit as medicines flow in world trade. ${ }^{67}$

In so far as international rules regarding innovation, intellectual property and access to medicines are concerned, the subject matter is principally being addressed outside the WTO in bilateral and regional settings. The capacity of WTO dispute settlement to control the implementation of IP-related rules may dissipate as the locus of trade regulation shifts to other arenas. It is not clear whether there will be a way of moving the centre of rule-making and interpretation back to Geneva, as the number of Members and their disparate interests have rendered decision-making extraordinarily difficult, and it is difficult to foresee the consequences of these changing circumstances.

\section{THE ROLE OF NGOS}

$\mathrm{N}_{\mathrm{in}}^{\circ}$

-governmental organisations have played a key role in draw-

ing attention to inequities in the global medicines supply chain, and to research gaps affecting individuals living in developing countries. Without the persistent pressures applied by NGOs, the Doha Declaration would not have come about. During the last decade, the role of NGOs has evolved. A number of the prominent organisers of the access to medicines campaign in the late 1990s worked to establish research-based foundations and related non-profit entities, such as the Drugs for Neglected Diseases initiative (DNDi). The Medicines Patent Pool (MPP) was pioneered by prominent figures in the first wave of the access to medicines movement. These are just two of a number of such developments.

67 Article 66.2 of the TRIPS Agreement places an affirmative obligation on developed WT Members to provide incentives for the transfer of technology to least-developed Members. It is important that the impending 2016 deadline for least-developed country (LDC) compliance with patent and data protection rules be extended to allow the mandate of Article 66.2 to be fulfilled. These initiatives are supported by various governments and multilateral organisations. The United States recently suggested that it might not support the extension beyond 1 January 2016 of the transition arrangement for least developed countries to forgo providing patent and data protection in the pharmaceutical sector. The EU declined to endorse an extension at this stage,
As entities such as DNDi and the MPP have moved into the practical aspects of developing and supplying drugs and vaccines, they have developed relationships with the originator industry companies. These companies are viewed by access-oriented NGOs as blocking access to medicines through the registration and enforcement of patents, marketing exclusivity rights and so forth With regard to the MPP, some NGOs standing outside of these relationships have turned equally, if not more stridently, to criticising the arrangements being negotiated by the MPP to supply important medicines.

The leaders of the first wave of the access to medicines movement have engaged in practical negotiations aimed at improving the well-being of a substantial number of individuals in lowincome countries. For the author of this paper, this is a pragmatic and useful way of addressing existing problems within a reasonable period of time. If the result of compromise is even greater public pressure on the originator industry from NGOs, the incentive for these companies to compromise is significantly diminished. The best approach for the MPP may be to seek to rally support from the middle, that is, from those who believe that some compromise is preferable to the absence of practical action.

\section{INTEGRATED GLOBAL MEDICINES POLICY 68}

WHO, WIPO and the WTO share the characteristic of being located in Geneva, Switzerland. This geographic characteristic has positively facilitated interaction among members of their secretariats, and has also helped to inform the global diplomatic corps that populates Geneva on a rotating basis. Similarly, the charter functions of these institutions are at the intersection of public health and intellectual property policy, and provide a logical focal point for the consideration of future trends in global medicines policy. However, these three institutions functioning 
cooperatively omit key elements of what is needed to appropriately provide a sustainable supply of medicines, especially for developing countries.

The first and most obvious gap concerns financing. None of them - WHO, WIPO or the WTO - is positioned to develop and/or implement a global financing mechanism for the purchase and distribution of medicines. Although each might be capable of overseeing the negotiation of an international instrument involving contributions from their member states to some form of fund, these institutions do not have the experience or built-in capacity to manage such an undertaking. The logical fourth institution, in terms of financing, is the World Bank, which is chartered to provide loans and direct financing for development. The World Bank does a considerable amount of work on public health issues, but is largely disassociated from the Geneva institutions.

Procurement-related organisations, such as the Global Fund, UNICEF and UNITAID, each have relationships with WHO, but each functions with an independent mission.

The United Nations Conference on Trade and Development (UNCTAD) is working with WHO on projects involving the transfer of technology to facilitate the production of medicines in developing countries.

Philanthropic organisations and product development partnerships (PDPs)/public-private partnerships (PPPs) are playing an increasingly important role in promoting R\&D, and in the supply of products. This includes organisations such as the Bill \& Melinda Gates Foundation and DNDi and, most recently, the Medicines Patent Pool.

Intergovernmental organisations (IGOs) such as the South Centre have developed specialised expertise on the relationship between intellectual property and public health.

NGOs concerned with innovation and access to medicines have been primary movers in causing governments and multilateral organisations to act. NGOs such as MSF, Oxfam, Knowledge Ecology
International (KEI), Health Action International (HAI) and Third World Network (TWN) have brought to public attention the needs of individuals around the world. NGOs such as the International Centre for Trade and Sustainable Development (ICTSD) have developed substantial expertise in analysing policy issues involving the intersection of trade, intellectual property and access to medicines.

It may be worth considering the establishment of an institutional arrangement that brings together representatives from each of these institutions and organisations for the purpose of information-sharing and formulation of strategic long-term planning on innovation and access to medicines. Something in the nature of a 'Global Medicines Coordination Council' could help identify the most urgent problems and methods for financing, and achieve solutions to them.

\section{SUSTAINABILITY}

Tn some measure, problems associated with access to medicines 1 may be intensifying as an unintended consequence of advances in economic development. During the past decade, several largereconomy developing countries have emerged as engines of global economic growth. As people in these countries unsurprisingly take advantage of improved standards of living, total global capacity to meet resource demands is strained. Governments face budgetary pressure in diverse areas, including food and energy supply. Less economically advanced developing countries struggle to help their people meet the basic needs for nutrition and housing. Health care budgets are affected. Governments everywhere are struggling to sustain local services for their own people. It becomes more difficult to make contributions for foreign assistance. If it were not apparent in 2001, it is clear today that reliance by developing countries on contributions and goodwill for necessary medicines is a serious issue that demands attention. The means by which medicines are supplied must be placed on a sustainable footing that is not subject to the ebb and flow of 
capital and natural resource markets, but, instead, functions methodically to meet the needs of the world's population. This is an enormous challenge facing all stakeholders in the medicines dialogue.

The science and technology by which medicines are developed and supplied is enormously complex and the problem of financing is vexing. Much of the progress in addressing critical medicines needs over the past decade has been achieved through a willingness on the part of wealthier countries to support developing countries, including through contributions from charitable foundations. A transition to sustainable medicines supply for developing countries will require changes in the way the global system is currently organised. Improved sources of financing for the provision of essential medicines must be developed. The private sector must be incentivised to develop new drugs and vaccines, yet without depriving patients of needed treatments. The medicines sector needs to be refocused towards rational prescribing and affordable pricing. Substantial improvements need to be made in the infrastructure of supply, including the regulatory infrastructure associated with approvals and inspections. This is the challenge of sustainability. The multilateral institutions could best assist in meeting the challenge by promoting cooperation among the stakeholders on all sides of the political and economic spectrum interested in achieving practical solutions. 
